\title{
SISTEM PAKAR DIAGNOSA KERUSAKAN DAN PERKIRAAN BIAYA SERVIS HANDPHONE PADA TOKO FELIX'Z MOBILE TANJUNGPINANG
}

\author{
Wanhendra ${ }^{1}$, Darmawan Mega Permana ${ }^{2}$, Dian Novryanto ${ }^{3}$ \\ ${ }^{1,2,3}$ Sekolah Tinggi Teknologi Indonesia Tanjungpinang \\ Jln. Pompa Air No. 28 Tanjungpinang Kepulauan Riau Indonesia \\ ${ }^{1}$ wan.itproject@gmail.com \\ 2darmawan_mega05@yahoo.com \\ 3iannovryanto21@gmail.com
}

\begin{abstract}
Intisari- Toko Felix'z Mobile adalah sebuah toko yang memberikan jasa servis handphone serta menjual berbagai macam aksesoris handphone yang berlokasi di Jalan Bridjen Katamso km 2 Tanjungpinang, Kepulauan Riau. Dalam Penlitian ini penulis akan membangun sebuah sistem pakar pada Toko Felix'z Mobile. Sebuah Pengecekan dilakukan secara manual dalam artian masih menggunakan alat elektronik untuk mengecek kerusakan yang terjadi pada handphone tersebut. Dikarenakan hal tersebut membutuhkan waktu yang lama sehingga servis handphone cukup lama. Perangkat lunak yang digunakan sebagai alat bantu untuk penelitian serta perancangan sistem baru yaitu Menggunakan Java Netbeans 8.1, dan Database yaitu MySQL Front. Hasil perkembangan dari sistem diharapkan dapat memberikan potensi kerja yang cepat dan akurat serta efisien sehingga dapat meningkatkan potensi toko.
\end{abstract}

Kata kunci - Servis, Java Netbeans, Handphone, Sistem Pakar, Kerusakan Handphone

Abstract - Toko Felix'z Mobile is a shop that provides cellphone services and sells various kinds of cellphone accessories, located on Jalan Bridjen Kata mso km 2 Tanjungpinang, Riau Islands. In this research the author will build an expert system at the Felix'z Mobile Store. A check is carried out manually in the sense that it is still using an electronic device to check the damage that has occurred to the cellphone. Due to this it takes a long time so the cellphone service is quite long. The software used as a tool for research and design of new systems is using Java Netbeans 8.1, and the database is MySQL Front. The results of the development of the system are expected to provide fast, accurate and efficient work potential so as to increase the potential of the shop.

Keywords - Door Security System, Arduino Application, Fingerprint Sensor, Ultrasonic Sensor and Fingerprint.

\section{Pendahuluan.}

\section{A. Latar Belakang}

Teknologi sudah sangat tumbuh dengan pesat sehingga banyak sekali manusia yang membutuhkan teknologi. Salah satu teknologi yang telah dibuat yaitu handphone. Handphone selain berfungsi untuk berkomunikasi, handphone juga digunakan untuk belajar, melalukan browsing, dan lainnya.

Semakin canggih handphone pada saat ini makin juga sering terjadi kerusakan yang tidak diinginkan oleh penggunanya. Sudah banyak sekali handphone yang memiliki harga tinggi dengan kualitas yang tinggi juga. Akan tetapi hal itu membuat harga sparepart dari handphone tersebut juga tinggi.

Contoh handphone dengan harga sparepart yang tinggi yaitu handphone yang menggunakan sistem IoS yaitu Iphone. Bahkan jika handphone tersebut rusak total (keseluruhan) maka sparepart yang harus diganti harganya bisa melebihi harga Iphone sendiri.

Dari hal tersebut dapat disimpulkan bahwa menggunakan handphone yang masih menggunakan sistem Symbian lebih tahan lama dan harga sparepartnya juga tidak terlalu mahal.
Selain Symbian ada juga handphone dengan sistem Android dengan harga sparepart yang murah.

Akan tetapi terkadang seorang teknisi pun tidak bisa mengirakan apa yang terjadi pada handphone yang rusak tersebut. Seperti jika saja handphone android yang mati total. Bisa saja baterai yang rusak, bisa juga kerusakan pada IC (Intergrated Circuit). Contoh juga seperti android yang saat dihidupkan hanya muncul logo/merk handphone tersebut. Bisa diperkirakan bahwa kerusakan handphone tersebut yaitu kerusakan pada sistem handphone tersebut yang seharusnya handphone tersebut di install ulang menggunakan flash.

Dari penjelasan diatas penulis menyimpulkan bahwa penulis akan membuat suatu sistem yang memudahkan pihak toko untuk melakukan sebuah diagnosa kerusakan pada handphone tersebut. Dengan menggunakan sebuah sistem pakar dengan aplikasi java Netbeans 8.1.

Dengan sistem pakar ini teknisi dapat melakukan sebuah pengecekan kerusakan handphone tersebut tanpa menunggu lama lagi. Pekerjaan teknisi pun akan lebih mudah dan cepat. Selain itu admin juga mampu menyimpan data servis dan mencari data sparepart untuk biaya servis handphone. 
Dari permasalahan diatas penulis mencoba membahas pemecahan permasalahan tersebut dengan judul penlitian "SISTEM PAKAR DIAGNOSA KERUSAKAN DAN PERKIRAAN BIAYA SERVIS HANDPHONE PADA TOKO FELIX'Z MOBILE TANJUNGPINANG”.

\section{B. Identifikasi Masalah}

Dari Latar Belakang tersebut, maka penulis dapat mengidentifikasikan masalah sebagai berikut:

1) Teknisi kurang cepat dalam pengecekan kerusakan handphone.

2) Pengecekan kerusakan handphone masih menggunakan alat seadanya yang digunakan teknisi seperti power supply, multimeter, dan lainnya.

\section{Batasan Masalah}

Berdasarkan dengan latar belakang yang telah diuraikan, agar pembahasan dalam penelitian ini tidak terlalu meluas maka dibatasi hal-hal sebagai berikut :

1) Teknisi mampu melakukan pencarian kerusakan handphone dengan sistem pakar dengan cepat dan mudah dan dapat menemukan solusi yang tepat untuk memperbaiki handphone yang rusak.

2) Target utama dari pembuatan sistem ini adalah mempercepat dan mempermudah pekerjaan teknisi.

3) Pembuatan sistem ini menggunakan aplikasi java Netbeans 8.1.

4) Mempercepat pencarian data servis dan harga sparepart berserta biaya servisnya.

5) Cara pengerjaannya adalah admin menjawab pertanyaan dari program yang telah dirancang dengan memilih ya atau tidak sehingga nantinya program akan memberikan hasil diagnosa kerusakan handphone tersebut.

\section{Metodologi Pengumpulan Data}

\section{A. Studi Pustaka}

Studi pustaka dilakukan dengan cara mempelajari teoriteori dari buku-buku yang berhubungan dengan pemelitian ini.

\section{B. Studi Lapangan}

Studi lapangan dilakukan dengan cara melibatkan toko secara langsung. Hal ini berfungsi untuk mendapatkan informasi-informasi untuk mengumpulkan data dan keterangan yang berhubungan dengan permasalahan yang diteliti.

\section{Studi Lapangan}

Studi lapangan dilakukan dengan cara melibatkan toko secara langsung. Hal ini berfungsi untuk mendapatkan informasi-informasi untuk mengumpulkan data dan keterangan yang berhubungan dengan permasalahan yang diteliti.

\section{Wawancara}

Wawancara dilakukan dengan pakar handphone yang ada di Tanjungpinang yang bernama Bapak Marthin Halomoan Marpaung. Beliau mempelajari teknik elektro sejak kuliah. Memiliki sebuah konter servis yang berdiri sejak 2005 dirumahnya dan kemudian berkembang pesat dan sekarang konter tersebut terletak di KM 6 Tanjungpinang yang bernama Toko Microcell. Hasil servis handphonenya sudah tidak diragukan lagi di Tanjungpinang sehingga banyak sekali masyarakat memperbaiki handphone di Microcell.

\section{E. Observasi}

Dilakukan dengan cara pengamatan terhadap objek yang akan diteliti untuk mendapatkan data serta informasi yang dibutuhkan untuk melakukan pemecahan masalahnya.

\section{F. Riset Lapangan}

Riset lapangan dilakukan dengan cara mendatangi langsung lokasi penulis dan pengumpulan data yang akan diteliti dilakukan langsung dengan pihak toko.

\section{G. Metode Pengembangan Sistem}

Metodologi yang digunakan penulis untuk melakukan penelitian ini adalah metode waterfall. Dimana langkahlangkah metode waterfall untuk melakukan penelitian ini adalah sebagai berikut :

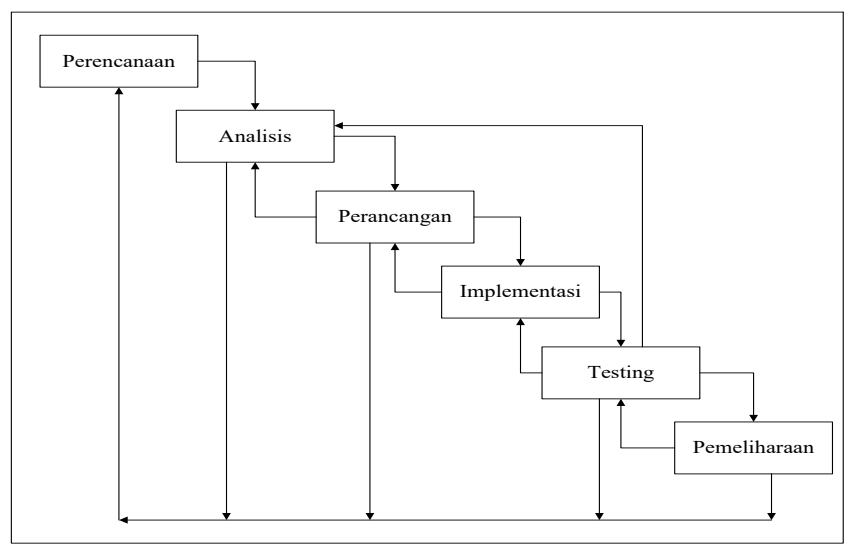

Gambar 1. Metode Waterfall [1]

Berikut ini merupakan penjelasan dari metode waterfall:

1) Analisis (Analysis)

Penulis melakukan analisis pengumpulan kebutuhan tentang kebutuhan perangkat lunak agar dapat dipahami spesifikasi perangkat lunak seperti apa yang sesuai dengan keinginan dan kebutuhan user.

2) Desai (Design)

Pada tahap ini penulis mendesain pembuatan program perangkat lunak termasuk sturktur data, arsitektur perangkat lunak, rancangan antar muka dan melakukan prosedur pengodean menggunakan Entity Relationship Diagram, Logical Relational Structure dan Struktur Navigasi.

3) Pengkodeaan (Coding)

Dalam pembuatan website ini, penulis menggunakan bahasa pemrograman PHP, HTML, CSS, Javascript. Dan web server yang digunakan penulis menggunakan paketan dari XAMPP, dibantu dengan Adoe Dreamweaver 6 sebagai teks editor yang digunakan penulis dalam menulis kode program.

4) Pengujian (Testing) 
Penulis melakukan pengujian dengan metode black box untuk menguji sistem yang dirancang agar dapat diukur sekaligus dapat diketahui kesalahannya.

5) Pemeliharaan (Maintenance)

Dalam tahapan ini, sistem diinstal dan mulai digunakan. Selain itu juga memperbaiki error yang tidak ditemukan pada tahap pembuatan. Dalam tahap ini juga dilakukan pengembangan sistem seperti penambahan fitur dan fungsi baru.

\section{LANDASAN TEORI}

\section{A. Pengertian Sistem}

Secara umum setiap organisasi selalu memiliki suatu sistem informasi yang diperlukan untuk berbagai tujuan, seperti mengumpulkan, menyimpan, melihat dan menyalurkan informasi. Sistem informasi dapat terbentuk karena didorong oleh kebutuhan akan informasi yang terus meningkat yang dibutuhkan oleh pengambil keputusan.

Didalam mendefinisikan sebuah sistem, ada yang menggunakan suatu penekanan terhadap prosedur dan penekanan terhadap komponen atau elemennya. Sistem juga bisa dikatakan suatu jaringan kerja dari prosedur-prosedur yang saling berhubungan, berkumpul bersama-sama untuk melakukan suatu kegiatan atau untuk menyelesaikan suatu sasaran yang tertentu[2].

\section{B. Pengertian Informasi}

Informasi merupakan data yang sudah diolah yang memiliki arti dan ditujukan untuk seseorang, organisasi ataupun siapa saja yang membutuhkan. Informasi dapat juga didefinisikan sebagai suatu pertambahan dalam ilmu pengetahuan yang menyumbangkan kepada konsep kerangka kerja yang umum dan fakta-fakta yang diketahui[3].

\section{Pengertian Sistem Informasi}

Sistem informasi adalah suatu sistem dalam suatu organisasi yang mempertemukan kebutuhan pengolahan transaksi harian yang mendukung fungsi operasi organisasi yang bersifat manajerial dengan kegiatan strategi dari suatu organisasi untuk dapat menyediakan kepada pihak luar tertentu dengan informasi yang diperlukan untuk pengambilan keputusan. Dikatakan juga sebagai cara-cara yang diorganisasi untuk mengumpulkan, memasukkan, dan mengolah serta menyimpan data, dan cara-cara yang diorganisasi untuk menyimpan, mengelola, mengendalikan, dan melaporkan informasi sedemikian rupa sehingga sebuah organisasi dapat mencapai tujuan yang telah ditetapkan[4].

\section{HASIL DAN PEMBAHASAN}

\section{A. Perancangan Perancangan Sistem}

Suatu tahapan kegiatan yang dilakukan seseorang atau kelompok dalam merancang atau membuat sistem sebelum sistem dibuat dengan tujuan sistem yang dibangun sesuai dengan kebutuhan dalam memecahkan atau dengan kebutuhan pengguna. Gambar 2 adalah flowchart pada proses Sistem Pakar Diagnosa Kerusakan Handphone.

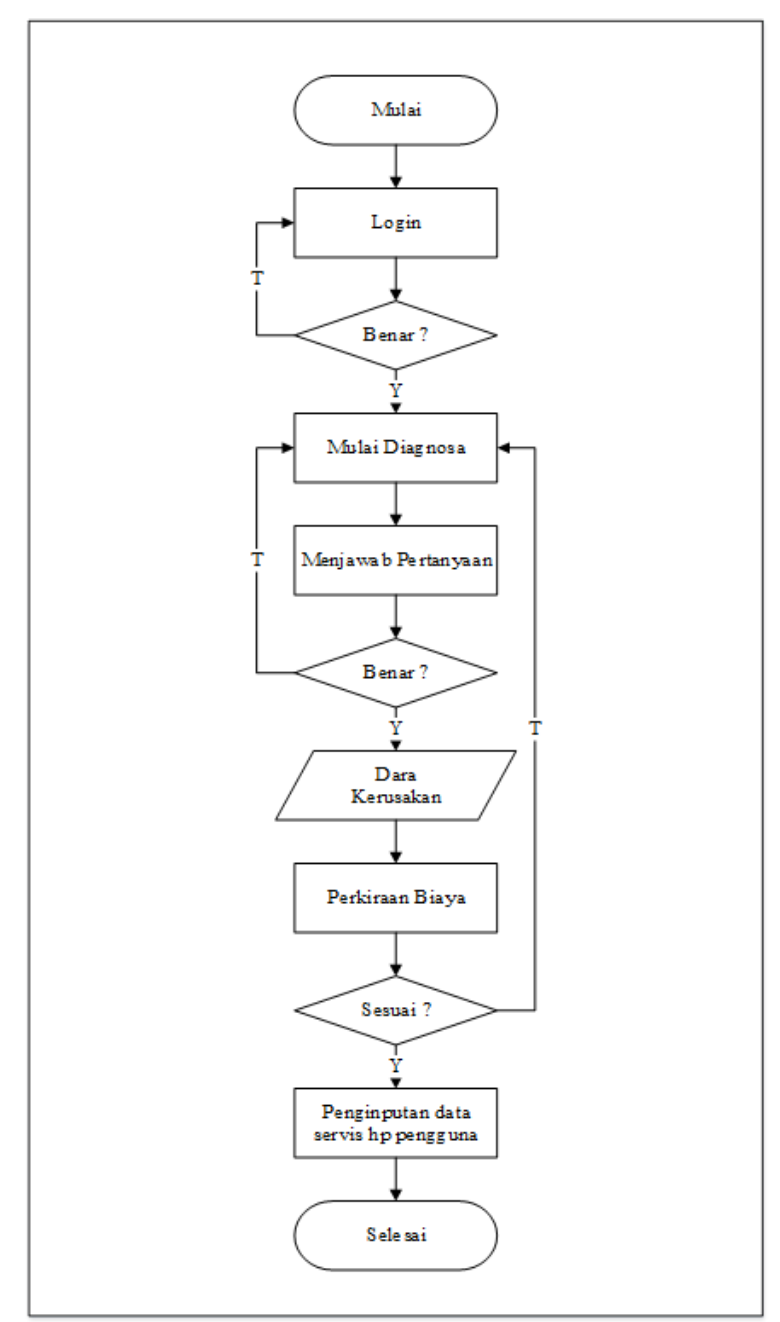

Gambar 2. Flowchart Sistem Pakar Diagnosa Kerusakan Handphone

\section{B. Komponen Pakar}

1) Basis Pengetahuan

Berikut adalah beberapa aturan yang ada pada program prolog diagnosa kerusakan Handphone.

a. Fakta Pengetahuan Prolog Kerusakan Handphone Dalam Fakta pengetahuan ini berisikan nama nama dari kerusakan handphone beserta gejala kenapa bisa terjadi kerusakan tersebut.

TABEL I

FaKta Pengetahuan Prolog

\begin{tabular}{|c|c|c|c|}
\hline $\begin{array}{c}\text { Kode } \\
\text { Kerusakan }\end{array}$ & $\begin{array}{c}\text { Nama } \\
\text { Kerusakan }\end{array}$ & $\begin{array}{l}\text { Kode } \\
\text { Gejala }\end{array}$ & $\begin{array}{c}\text { Nama Gejala } \\
\text { Kerusakan }\end{array}$ \\
\hline KR1 & $\begin{array}{l}\text { Mati Total } \\
\text { Blank }\end{array}$ & KGJL1 & Resistor \\
\hline KR2 & $\begin{array}{l}\text { Hitam/Putih } \\
\text { Tidak Bisa } \\
\text { Sentuh }\end{array}$ & KGJL2 & Ic Lampu \\
\hline KR3 & $\begin{array}{c}\text { Layar } \\
\text { Hp Mode }\end{array}$ & KGJL3 & Lampu Lcd \\
\hline KR4 & Logo & KGJL4 & Led \\
\hline
\end{tabular}




\begin{tabular}{|c|c|c|c|}
\hline KR5 & $\begin{array}{c}\text { Low } \\
\text { Response/ } \\
\text { Lambat }\end{array}$ & KGJL5 & Socket Lcd \\
\hline \multicolumn{4}{|c|}{$\begin{array}{c}\text { TABEl I } \\
\text { FAKTA PENGETAHUAN Prolog }\end{array}$} \\
\hline $\begin{array}{c}\text { Kode } \\
\text { Kerusakan }\end{array}$ & $\begin{array}{c}\text { Nama } \\
\text { Kerusakan }\end{array}$ & $\begin{array}{l}\text { Kode } \\
\text { Gejala }\end{array}$ & $\begin{array}{c}\text { Nama Gejala } \\
\text { Kerusakan }\end{array}$ \\
\hline KR6 & $\begin{array}{c}\text { Tidak Bisa } \\
\text { Buka } \\
\text { Aplikasi } \\
\text { Hp Cepat }\end{array}$ & KGJL6 & Layar sentuh \\
\hline KR7 & $\begin{array}{c}\text { Panas } \\
\text { Batterai } \\
\text { Cepat }\end{array}$ & KGJL7 & Socket Layar Sentuh \\
\hline KR8 & & KGJL8 & Ic Emmc \\
\hline \multirow[t]{7}{*}{ KR9 } & $\begin{array}{l}\text { Mengisi } \\
\text { Daya }\end{array}$ & KGJL9 & $\begin{array}{l}\text { Versi Android Tidak } \\
\text { Cocok }\end{array}$ \\
\hline & & KGJL10 & Over Application \\
\hline & & KGJL11 & Ic Power \\
\hline & & KGJL12 & Over Charger \\
\hline & & KGJL13 & Batterai \\
\hline & & KGJL14 & Transistor \\
\hline & & KGJL15 & Button On/Off \\
\hline
\end{tabular}

Berikut adalah hubungan dari gejala kerusakan dan menjadi kerusakan handphone.

TABEL I

Fakta Pengetahuan Hubungan Gejala

\begin{tabular}{|c|c|c|}
\hline $\begin{array}{l}\text { Kode } \\
\text { Gejala }\end{array}$ & $\begin{array}{c}\text { Nama Gejala } \\
\text { Kerusakan }\end{array}$ & $\begin{array}{c}\text { Gejala Kerusakan } \\
\text { Dari }\end{array}$ \\
\hline KGJL1 & Resistor & KR1 \\
\hline KGJL2 & Ic Lampu & $\mathrm{KR} 1, \mathrm{KR} 2$ \\
\hline KGJL3 & Lampu Lcd & $\mathrm{KR} 1, \mathrm{KR} 2$ \\
\hline KGJL4 & Lcd & KR1,KR2,KR3 \\
\hline KGJL5 & Socket Lcd & $\mathrm{KR} 1, \mathrm{KR} 2, \mathrm{KR} 3$ \\
\hline KGJL6 & $\begin{array}{l}\text { Layar sentuh } \\
\text { Socket Layar }\end{array}$ & KR3 \\
\hline KGJL7 & Sentuh & KR3 \\
\hline KGJL8 & $\begin{array}{c}\text { Ic Emmc } \\
\text { Versi Android }\end{array}$ & KR1,KR4,KR5 \\
\hline KGJL9 & $\begin{array}{c}\text { Tidak Cocok } \\
\text { Over }\end{array}$ & KR1,KR4,KR5 \\
\hline KGJL10 & Application & KR1,KR4,KR5 \\
\hline KGJL11 & Ic Power & KR1,KR7,KR8,KR9 \\
\hline KGJL12 & Over Charger & KR1,KR7,KR8,KR9 \\
\hline KGJL13 & Batterai & KR1,KR7,KR8,KR9 \\
\hline KGJL14 & Transistor & KR1 \\
\hline KGJL15 & Button On/Off & KR1 \\
\hline
\end{tabular}

\section{b. Tree of Knowledge Base}

'Tree of Knowledge Base atau biasa disebut pohon basis pengetahuan adalah hubungan antara gejala kerusakan dan kerusakan yang dirancang hanya menggunakan sebuah kode kerusakan dan gejala kerusakan yang menjadi sebuah pohon seperti layaknya silsilah keluarga. Dalam hal ini penulis membuatnya dengan mengambil kerusakan yang paling parah dahulu kemudian menjadi kerusakan yang terkecil, dapat dilihat pada gambar 3 berikut ini.

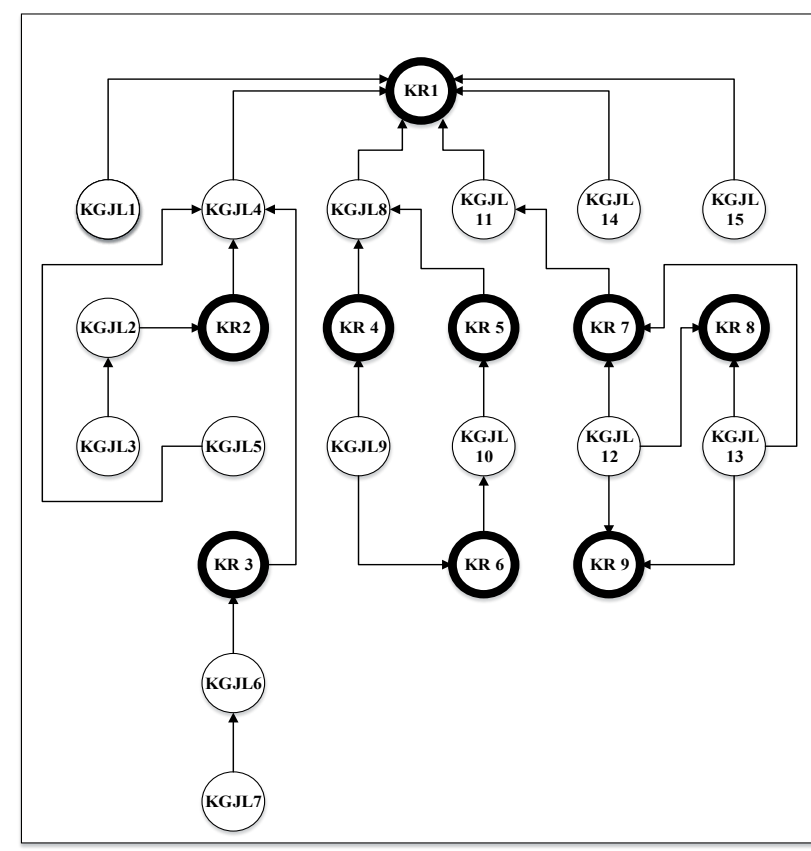

Gambar 3. Tree of Knowledge Base

\section{KESIMPULAN}

Dari seluruh laporan dapat disimpulkan bahwa pihak toko sangat membutuhkan sistem pakar untuk mempercepat pekerjaan dan mempermudah pekerjaan, selain itu admin toko mampu mengoperasikan sistem dengan mudah dan dapat memberitahukan kepada pelanggan yang datang tentang informasi kerusakan handphone dan berapakah biaya yang harus dibayar jika handphone tersebut mengalami kerusakan. Tentunya hal ini sangat memperudah pihak toko dan pihak toko pun dapa meraih keuntungan yang banyak. Dan pelanggan pun tidak perlu khawatir tentang biaya servis yang sebelumnya telah diberitahukan oleh admin seberapa besar biaya yang harus dibayar oleh pelanggan. Selain itu admin juga dapat menyimpan data servis yang masuk pada toko tersebut sehingga sedikit terhindar dari namanya yang kehilangan nota servis. Dengan menyebutkan nama ataupun nomor handphone pelanggan, admin bisa mengetahui status handphone pengguna tersebut. Tentunya dengan adanya sistem pakar ini teknisi pun telah dipermudah pekerjaannya sehingga mampu memaksimakan pekerjaannya. Kerjasama dari admin dan teknisipun sangat dibutuhkan sehingga lebih cepat lagi dan akurat dalam mendiagnosa kerusakan handphone tersebut karena program ini hanyalah sebatas perantara dan mempermudah pekerjaan

\section{REFERENSI}

[1] Y. Verdi., 2013, Rekayasa Perangkat Lunak Berorientasi Objek, Andi, Hal. 18.

[2] Jogiyanto, HM, MBA, Akt, 2015, Analisis dan Desain,Yogyakarta : Andi, Hal.1.

[3] Tyson, S. P. Jaluanto, 2016, Sistem Informasi Manajemen, Yogyakarta : Deepublish, Hal.19. 
Bangkit Indonesia, Vol. VII, No. 01, Bulan Maret 2018

[4] Krismiaji, 2015, Sistem Informasi Akuntansi (Edisi 4), Yogyakarta : UPP STIM YKPN, Hal.15. 